\title{
MARIA E LUISA: UM OLHAR SOBRE A PERSONAGEM FEMININA NA FICÇÃO QUEIROSIANA E EM UM ROMANCE MORAL ${ }^{1}$
}

Carolina Regina Morales ${ }^{2}$

RESUMO: O presente trabalho visa propor aproximações e dessemelhanças entre as obras A Virgem da Polônia de José Joaquim Rodrigues de Bastos e O Primo Basílio de Eça de Queirós, elucidando tópicos comuns a ambos os livros, bem como as distintas estratégias empregadas pelos respectivos autores a fim de comover e/ou demover o público.

PALAVRAS-CHAVE: Portugal; Eça de Queirós; Conselheiro Bastos; Seculo XIX.

ABSTRACT: this work aims to present likeness and diferences among $A$ Virgem da Polonia written by José Joaquim Rodrigues de Bastos and O Primo Basilio by Eça de Queirós, regarding common topics to both, as well as the various skills employed by the authors to move their readers.

KEYWORDS: Portugal; Eça de Queirós; Conselheiro Bastos; XIX Century.

A virgem da Polônia ${ }^{3}$, classificado por Luis Sobreira ${ }^{4}$ como "romance moral", foi publicado primeiramente em 1847, tendo-se tornado um dos quatro maiores best sellers do período, com edições posteriores que se estenderam até a década de 70. Além do notável caráter religioso, uma das justificativas para tamanho êxito pode ser resumida na "permanência de uma procura importante de literatura edificante no preciso momento em que se laicizam os interesses da elite culta" (SOBREIRA, 2001, p. 3).

\footnotetext{
${ }^{1} \mathrm{O}$ texto que vamos apresentar resulta das reflexões e questionamentos suscitados pelo curso de PósGraduação A Ascensão do Romance Português, ministrado no primeiro semestre de 2008 pelo Prof. Dr. Paulo Motta, que aqui recebe nosso agradecimento.

2 Mestranda em Literatura Portuguesa pela Faculdade de Filosofia, Letras e Ciências Humanas da Universidade de São Paulo.

3 A edição da qual nos servimos para este trabalho foi a quinta, cuja referência completa é: BASTOS, José Joaquim Rodrigues de. A Virgem da Polônia. Porto: Cruz Coutinho, 1860.

4 SOBREIRA, Luis. "Uma imagem do campo literário português no período romântico través dos best sellers produzidos entre 1840 e 1860”. Artigo apresentado no IV Congresso Internacional da Associação Portuguesa de Literatura Comparada. Évora: 2001.
} 
Esta obra representa uma concepção que defende o caráter intervencionista da literatura na sociedade, que supostamente carecia de instrução, orientação, ou antes, de um modelo comportamental "digno" e "louvável", em oposição ao materialismo e laicismo presentes no período. De acordo com Northop Frye,

(...) Considerar a literatura como uma unidade em si mesma não significa excluí-la de um contexto social: ao contrário, torna-se bem mais fácil distinguir que lugar ela ocupa na civilização. A crítica terá sempre dois aspectos, um voltado em direção à estrutura da literatura e outro apontando para outros fenômenos culturais que constituem o ambiente social da Literatura.(FRYE, 1973, p. 22).

De fato, tanto a obra do Conselheiro Bastos como a produção ficcional queirosiana da década de 70 adquirem tons bastante peculiares quando perscrutadas à luz de seus respectivos cenários culturais. De certo modo, pode-se dizer que $A$ Virgem da Polonia e $O$ Primo Basílio têm a pretensão de, a sua maneira, disciplinar o público moralizando e conduzindo a sociedade lusitana tal qual uma consciência coletiva auto-imputada. Trata-se de uma concepção na qual o "homem de letras" reveste-se de um caráter de guia, antena de seu povo, tomando para si a tarefa de ofertar, através de sua obra, modelos exemplares a (não) serem emulados. Cabe destacar que ambos elegem, como personagem principal, figuras femininas, alvos dos elogios ou vitupérios. Outro dado que aproxima os autores oitocentistas e apresenta certa consonância com essa configuração de autor/interventor é o fato de ambos, Eça e Bastos, manterem vínculos com a política em Portugal.

No entanto, parece que as semelhanças entre eles terminam por aqui. Afinal, onde um vê ceticismo, o outro busca a moralidade; onde um configura a fé, o outro externa descrença; enquanto um clama por revolução, o outro assenta-se no reacionarismo. Como seria possível, portanto, que em 1878, ano de lançamento de O Primo Basílio, ainda subsistissem leitores para A Virgem da Polônia?

Tal questão é agravada pelo dado manifesto de o público alfabetizado e leitor em Portugal ser tão numericamente restrito. Em uma nação como a Inglaterra, poder-se-ia sem problemas separar o público alvo de Bastos de outro mais apto ao consumo das obras de Eça de Queirós, assumindo que se tratariam de nichos mercadológicos distintos; todavia, pensando-se em Portugal, tal hipótese é inviável. 
Mas, como vimos anteriormente, há pontos em comum, similaridades que aproximam as obras. A partir de agora, deter-nos-emos na análise comparativa dos enredos, bem como das personagens destes.

A Virgem da Polônia tem um argumento atípico para um romance português do século XIX: uma mulher, altamente dotada de recursos retóricos, com um repertório enciclopédico absurdamente vasto para um ser humano do sexo feminino de sua época (seu conhecimento, elucidado nos infindáveis discursos e argüições, abrange desde a Antiguidade Clássica, com as citações de Cícero e Calígula, até Marat e a Revolução Francesa, correlacionalmente próxima vinte anos ao desenrolar da ação), desloca-se pela Europa e pelo Oriente pregando a fé católica - a "única e verdadeira" - e convertendo todo e qualquer ser humano que se lhe apareça adiante. Os únicos imunes aos seus encantos discursivos são os russos, caracterizados na narrativa como irracionais e brutos, animalizados - não dignos, portanto, da salvação. Na época, a Polônia estava sob o jugo da Rússia czarista.

Como bem destaca Frye,

(...) um mito religioso de interesse tende gradativamente, na medida em que evolui, a especializar-se em outro universo, e durante o século XVIII a crescente ineficácia da componente politicamente revolucionária do cristianismo, apesar de alguns movimentos como o metodista, ocasionou uma crise. O monopólio cristão do mito ocidental de interesse começou a ceder terreno e uma série de mitos novos e mais seculares passou a dividir campo com ele. (FRYE, 1973, p. 48).

É esse terreno perdido no século anterior que Maria, ao início do XIX, vai tentar reaver, tal qual uma amazona na Reconquista, munida, em lugar de lanças e espadas, das palavras e sedenta não de sangue mouro, mas de almas que resgatará do abismo das "fés obscuras". De fato, como conclui o crítico norte-americano, "Naturalmente, houve muitos que insistiram em que o verdadeiro mito do interesse poderia ser encontrado num cristianismo revigorado, e desde então a produção de tais manifestações tem sido uma verdadeira indústria para a cultura". (FRYE, 1973, p. 56).

Sendo os poloneses uma população marcadamente católica, bem como exemplo europeu de resignação ao sofrimento e persistência na fé ante as adversidades - pois estiveram durante boa parte de sua história baixo o domínio de outras nações, ora Rússia, 
ora Alemanha - tornam-se uma boa opção para a nacionalidade de uma moça que se vai insurgir como exemplo moral para os conterrâneos de Bastos, que dota sua criação das seguintes características:

(O pai) mandou-lhe ensinar, além das prendas ordinárias se seu sexo, as línguas que mais lhe convinham, (...), o latim, o grego, o hebreu, the chegaram a ser tão familiares como poderiam ser línguas mortas há tantos séculos.

Ella passou a applicar-se nas Sciencias com o mesmo ardor com que se aplicara às línguas, Religião, história, philosophia, música, pintura, sciencias exactas, tudo estudava, aprendia tudo, e não se saciava nunca. Porém seu pai procurava sempre conservar em um justo equilíbrio seu coração e sua inteligência, sua imaginação e sua razão, e proporcionava quanto podia a sua aplicação às suas forças, os seus estudos à sua idade.

Chegou a adquirir uma quantidade de conhecimento, que a habilitavam a disputar vitoriosamente com alguns sábios escolhidos que concorriam a sua casa: mas nunca o fazia sem que seu pai lho ordenasse, e elle lho ordenava muitas vezes, assim pelo prazer que lhe resultava de a ver triunfar (BASTOS, 1860, pp. 46-47).

Como exposto, temos que Maria, em lugar de contentar-se com corte e costura, bordado, piano, desenho, geografia, uma ou outra língua estrangeira moderna e canto, tem a seu favor um vasto background. Tal qual Heloise, que no século XII podia realizar argüições com Abelardo sobre questões filosóficas e teológicas durante horas, ou Lady Jane Grey, que no século XVI dedicou -se a estudar com afinco os fundamentos da fé protestante e correspondia-se regularmente com os maiores pensadores contemporâneos seus, Maria pode ser considerada um exemplo atípico ao comportamento usual feminino de sua época; no entanto, ao contrário de Heloise e Lady Jane (que apresentam ceticismo ou ressalvas em relação aos dogmas da Igreja Católica), ela assenta-se em sua fé como uma crença que não comporta dúvidas ou introspecções em relação a si mesma: trata-se do tautologismo da fé pela fé. Maria tem fé, por isso a defende; e defende sua fé, porque a tem. Não sai desse círculo nunca; seus conhecimentos são-lhe úteis tão-somente à tarefa de demover os demais de práticas vis que lhes custariam as almas - em nenhum momento a encontraremos refletindo sobre a questão da pertinência da própria prática de sair pelo mundo recriminado os semelhantes em nome de sua "Verdade" ou antes analisando logicamente as bases e fundamentos desta. Já no excerto apresentado vemos que todo o repertório de Maria sempre está limitado a uma instância maior, seja o pai, sem a ordem do qual não poderia dialogar 
com os convidados, ou a própria instituição católica, cujos parâmetros de "aceitável” ou “inaceitável” norteiam suas ações. Além disso, ao pregar, ainda que indiretamente (uma vez que não pertence ao clero) o faz em seu nome.

Se, por um lado, a virgem da Polônia serve-se da razão para espargir sua crença inabalável pelos territórios que percorre, o oposto desta, a casualidade, também lhe é útil em alguns lances do enredo, como, por exemplo, o sonho profético (“um aviso celeste?", pergunta-se ela) que tem prevenindo-a de que saia de seu país, pois passará a ser perseguida pelos russos, e a vontade inexplicável de abrigar-se em uma igreja, na noite em que voltava de um tribunal onde defendera a necessidade de ser cuidarem dos poloneses feridos em tentativas de insurreição; nessa noite, sua casa fora invadida e seus pertences, confiscados exceto o crucifixo, salvo por seu admirador discreto. Por fim, outra intervenção do acaso ocorre quando Julia, apaixonada pelo médico egípcio, recém convertido por Maria, livra-se da "carga" de um casamento multi-étnico quando este é aniquilado durante o matrimônio sem quaisquer explicações. Tendo tanto a causalidade como a casualidade a seu favor, a virgem assim demonstra ter o auxílio da própria divindade que, além de dotá-la de talentos úteis às conversões, intervêm em casos de necessidade.

Com uma vida tão marcadamente comprometida ante os demais, não surpreende que a Maria mal se dê conta da perseguição de seu pretendente, o mesmo que lhe reouvera o crucifixo. Definitivamente, o matrimônio não se insere em seu horizonte; a visão que tem do sexo oposto não é das mais lisonjeiras:

Ella sabia que a mulher deve ser a sentinella vigilante se si mesma, estando, como quasi sempre está, cercada de inimigos; tendo-os em sua cabeça, em seu coração, em toda a sua pessoa, e em grande parte das pessoas que a comunicam.

(...)

Adoptou um sistema de recolhimento, persuadida de que assim conseguiria viver esquecida e não conseguiu.

A sua mão, que já em tempos de seu pai havia sido mui pretendida, depois de seu fallecimento, o continuou a ser, com dobrado empenho, por alguns senhores russos. Que respondia ella sempre? Eu sou Polaca. A sua vida, porém e a constância com que sempre repelliu semelhantes proposições, apresentados mesmo por parte dos mais ilustres Cavalheiros Polacos, mostravam bem que ella se tinha dedicado toda ao Senhor, e que rejeitaria o mais amável Príncipe mesmo, ou elle fosse nacional ou estrangeiro. (BASTOS, 1860, p. 106). 
O homem surge, portanto, como força inibidora do caminho da virtude e do equilíbrio. Maria rejeita, inclusive aqueles que, por definição, seriam dignos de uma união, em nome de um fervor religioso que visa dirigir todo e qualquer esforço às obras em nome da missão recoletora de almas desviadas. Semelhantemente às heroínas de Richardson na Inglaterra, Maria parece estar construindo um novo ideal do feminino, a fim de atender a uma demanda em ascensão de leitores. Talvez essa seja uma das razões para que o livro tenha suscitado tantas gratificações por parte da crítica entusiástica e do público, consumidor massivo da obra, enquanto que a configuração da personagem Luisa em $O$ Primo Basílio gere, por sua vez, escândalo.

A visão negativa do homem enquanto distúrbio na conduta virtuosa das moças encontra um excelente aparato se pensarmos na figura de Basílio, da obra de 1878 de Eça de Queirós. Janota, presunçoso e, o que resulta mais periclitante, entediado - ou seja, com disposição e tempo livre para seduzir a prima igualmente desocupada - o português afrancesado seria uma verdadeira visão do inferno para uma personagem com as características de Maria.

Por sorte, uma virgem configurada como a personagem de Bastos - que o repeliria sem sombra de dúvida - não é o alvo de Basílio, e sim uma moça que, longe se ser salvaguardada por uma vasta quantidade de exemplos morais e argumentos, com uma educação bastante lacunar condizente à época da ação, torna-se um entretenimento eficiente e é descartada no preciso momento em que deixa de sê-lo.

Da mesma forma que Maria, Luísa também está sob o jugo de uma instituição maior, que tolhe seus atos e vontades: na adolescência, a figura da mãe, que ela e o primo aguardavam adormecer para praticar as "liberdades" no sofá. Essa mesma mãe, alegrandose com o casamento da filha, um verdadeiro "descanso" para si, transmite essa autoridade para Jorge, cujo poder abrange desde a gestão dos empregados (adverte Luísa, logo na abertura do romance, que somente com seu consentimento esta poderia demitir Juliana) até a entrada ou não de visitas na casa (a de Leopoldina, por exemplo, já está manifestadamente interditada no primeiro capítulo do livro). Se o espaço simbólico ao qual Luísa quer ascender é a casa, pode-se dizer que falha completamente.

Assumindo-se a acepção da retórica como a arte da persuasão, ou seja, do uso da linguagem com o intuito de (de)mover o outro, Luísa, ao contrário de Maria, deixa entrever 
que não possui esse dom. Após uma acalorada recriminação por parte do marido, sobre a presença da amiga em sua casa, Jorge por fim lhe dá a oportunidade de contra-argumentar (ou corroborar) seu ponto de vista:

- Ora vamos, Luísa, tenho ou não tenho razão?

Luísa punha os brincos, ao espelho, atarantada:

-Tens. - disse.

- Ah! Bem!

E saiu, furioso.

Luisa ficou imóvel. Uma lagrimazinha redonda, clara, rolava-lhe pela asa do nariz, muito doloridamente. Aquela Juliana! Aquela bisbilhoteira! De má! Para fazer-lhe cizânia!

Veio-lhe então uma cólera. Foi ao quarto dos engomados, atirou com a porta:

- Para que foi você dizer quem estava ou deixou de estar? (QUEIRÓS, 1997, pp. 31-32).

Incapaz de dialogar com o esposo, a quem é hierarquicamente inferior segundo os parâmetros da época, Luísa vinga-se despejando sua intempérie emocional sobre quem lhe é socialmente inferior. A estrutura de instâncias que cerceiam o arbítrio de outrem somente será invertida, neste romance, quando Juliana tomar para si o controle da casa e Luísa o da vida íntima do casal, praticando com Jorge os diferenciais aos quais tivera acesso através das práticas com Basílio, em uma subversão dos parâmetros considerados na época como “aceitáveis" que só poderia acarretar tragédia, com a morte das citadas protagonistas femininas. Se Maria podia ser a representante de um novo ideal feminino em ascensão, Luísa evidentemente não pode seguir o mesmo percurso, pois uma vez em dissonância com os ideais da castidade, benevolência, resignação, religiosidade, temperança, etc., não suporta o peso da punição e morre. Diferentemente de Maria, não conta com a causalidade e casualidade a seu favor.

Contudo, antes do final patético, muitas peripécias ocorrerão no enredo, que evidencia o status social e a formação intelectual usual da mulher nesta sociedade burguesa lisboeta oitocentista. Por exemplo, nos primórdios da sedução da prima, Basílio entrega-lhe um presente muito peculiar - um crucifixo. Após afirmar que conhecera o papa em pessoa, "um velhinho muito asseado, já todo branquinho, vestido de branco, muito amável!" (QUEIRÓS, 1997, p. 65), ele entrega-lhe uma pretensa relíquia trazida pelo patriarca de Jerusalém e regalada pelo ápice do clero em Roma. No entanto, se o objetivo de Basílio era 
ofuscar Luísa com presentes hiperbólicos, falhou, pois este esbarra em uma das lacunas da educação da prima: a falta de crença religiosa. “- Não sou muito caturra nessas coisas” (QUEIRÓS, 1997, p. 65), responde ela, zombando. Se a forte presença do religioso foi uma das causas do êxito mercadológico d'A Virgem da Polônia, O Primo Basílio, de certo modo, mostra o que ocorre quando este é suprimido totalmente do horizonte feminino. Luísa não freqüenta a igreja, exceto para despistar o Conselheiro Acácio quando casualmente o encontra uma vez em seu caminho ao Paraíso, não ora (inclusive porque não sabe com que linguagem dirigir-se-ia a Deus) e, portanto, não possui o respaldo de quaisquer crenças ou códigos morais para deles apropriar-se como escudo ante o assédio do lascivo ex-noivo, com o qual tem um pacto de prazer e entretenimento, em essência, o mesmo proporcionado por suas leituras de Dumas Filho e Walter Scott, assim como o de sua relação com a amiga Leopoldina. Fugir à ociosidade e ao tedioso cotidiano de uma casa que não é governada por si própria é o caminho enveredado por Luísa. Não podemos negar o caráter ambíguo de prazer e êxtase que o fervor religioso aparentemente causa aos devotos; a arte já o demonstrou por diversas vezes, e um exemplo notável é a escultura de Bernini, O Extase de Santa Teresa.

Quanto ao que a falta de crenças religiosas acarreta na formação feminina, o próprio Eça discorre sobre o fato, por exemplo, em cartas a Teófilo Braga e em ensaios sobre a educação da mulher destacando a falta de princípios morais e religiosos, a ausência do estudo de ciências exatas, o excessivo trato por meio de babás e falta de asseio e hábitos salutares como evidentes falhas na educação das crianças do sexo feminino, que se tornam, portanto, inclinadas ao gosto por intrigas, enfraquecimento intelectual e debilidade de caráter e saúde.

Se, por um lado, tal temática encontra-se em ambas as personagens, Maria e Luísa, há outra que percorre caminho oposto, pois se encontra assoberbada em O Primo Basílio e ausente em $A$ Virgem da Polônia: o sexo. É interessante notar que, exceto por uma ou outra referência velada, como quando o pai de Júlia apaixona-se e casa com uma mulher que não é católica, deixando claro que se tratara de uma atração puramente sexual, o sexo encontrase banido da obra de Bastos, o oposto ao que ocorre no romance de Eça. Como destaca Ana Luisa Vilela, a respeito d'Os Maias (mas que pode ser igualmente aplicado no que concerne a $O$ Primo Basílio), 
O real moralismo de Eça - demonstrado de forma clarividente por Antonio Coimbra Martins em 'Eva e Eça' associou, evidentemente, Eros e sacrilégio. Assim, de uma forma sistemática, Eça proscreve e reescreve uma metafísica erótica. Demonstrando que o sistema de concupiscência queirosiana se funda no interdito sexual, Coimbra Martins evidenciou o modo como, em Eça o amor - pela sua denominação instintiva e carnal é representado como uma 'armadilha mortal', um pecado original degradante, que acarreta um castigo terrível e inelutável (VILELA, 1997, p. 57).

Se o sexo (esclarecidamente fora do casamento e negando-se a fins reprodutivos) é subvertido tendo como fim último o prazer, por si só, este é um ato passível de punição, tanto no discurso ficcional de $O$ Primo Basílio quanto no dogma católico. Além da questão da educação da mulher, do caráter intervencionista do homem de letras e da importância da religião na formação da mulher, parece que surge aqui outro ponto que nos possibilita aproximar as duas obras: o aspecto do destino enquanto dado indiscutível e inevitável no desfecho da personagem. Luísa e Juliana morrem, assim como o noivo egípcio de Julia, por desejarem algo além de suas respectivas alçadas.

Da mesma maneira que um dogma não deve ser questionado dentro da lógica racional, para um incrédulo tampouco há forma de expressão da qual servir-se para dialogar com Deus. Se Maria apresenta um incessante discurso que se fecha em si próprio e nunca falha em seu intento, não deixando lacunas em aberto para contestação do interlocutor, inclusive porque se vale dos conceitos e crenças deste para prever os contra-argumentos e refutá-los previamente, Luísa, pelo contrário, não é capaz de desafiar dialogicamente Jorge e Basílio; tampouco possui meios de expressão para dirigir-se a Deus, afinal, "Com que linguagem" (QUEIRÓS, 1997, p. 239) poderia fazê-lo? Com as mesmas idiossincrasias de suas conversas com Leopoldina? Pois esta é a única, de acordo com o enredo, com a qual se sente cômoda para dialogar. Hierarquicamente iguais, adulteramente irmanadas, Luísa e Leopoldina discutem e auxiliam-se mutuamente da mesma maneira que Sebastião com Jorge ou Julião - as esferas do masculino/feminino e do humano/divindade não se mesclam no âmbito do dialógico, uma vez que este pressupõe dois combatentes de igual status.

Se a personagem não possui força de expressão, seu criador, por outro lado, causou bastante rebuliço nos meios literários ao lançar a obra - talvez porque crítica e público estivessem mais habituados à literatura produzida em moldes mais semelhantes à Virgem 
da Polônia. Como destaca Beatriz Berrini, em "Os prefácios ensaísticos de Eça de Queirós”,

Os pareceres contrários, entretanto, não impediram a divulgação dos romances [O Primo Basílio e $O$ Crime do Padre Amaro] e sua recepção entusiástica pelo público português e brasileiro. Acrescente-se mais uma observação: tinha Eça perfeita consciência da realidade social: se os críticos caturras, com suas restrições, pretendiam salvaguardar a moral familiar, proteger inocentes donzelas, o nosso romancista apoiado em Feuillet, (que ele qualifica de 'castíssimo e idealíssimo') afirmava que, quando estas virgens pudicas, todas de branco, estão juntas, num canto da sala, têm conversas qui feraient rougir um singe, que fariam corar um macaco! - animal que era considerado a mais obscena das criaturas (BERRINI, 1997, p. 117).

Parece que Eça tinha suas ressalvas quanto ao modelo de donzela estandardizado tal qual o é na literatura de Bastos, ou talvez no conceito de exemplaridade mimética desse tipo de personagem, que não suscitaria a ânsia do público de imitá-lo. Prefere expor seu repúdio às bases mal erguidas da sociedade que vitupera através de um exemplo negativo, a ser rechaçado, como uma advertência aos leitores passíveis de chafurdarem no lodo da luxúria e da imbecilidade intelectual.

Desta maneira, este trabalho buscou perscrutar temas e aspectos presentes em ambas as obras, contrastando a forma peculiar empregada por cada autor para desvelá-los, tendo em vista as evidentes divergências estético-literárias e de posicionamento crítico entre os dois. Seja pela supressão ou superexposição da relação sexual, pela ausência ou exacerbo do discurso verbal explícito da personagem, pelo exemplo feminino inimitável ou humanamente falho e, como tal, passível de mazelas e contradições, o Conselheiro Bastos e Eça de Queirós apresentam-nos um panorama repleto de cenários e conceitos próprios do imaginário português oitocentista, que suscitam bastante interesse no que concerne à presença da personagem feminina em obras de autores notadamente preocupados em intervir e melhorar a sociedade, deficiente sob o ponto de vista de ambos, ainda que cada qual com postura divergente em relação ao outro.

\section{REFERÊNCIAS BIBLIOGRÁFICAS:}

BASTOS, José Joaquim Rodrigues de. A Virgem da Polônia. Porto: Cruz Coutinho, 1860. 
BERRINI, Beatriz. "Os prefácios ensaísticos de Eça de Queirós". In: MINÉ, Elza (org.) 150 anos com Eça de Queirós. São Paulo: Centro de Estudos Portugueses, 1997, pp.113119.

CAMPOS, A. Matos. Dicionário de Eça de Queirós. Lisboa: Caminho, 1988.

FRYE, Northop. O caminho crítico. São Paulo: Perspectiva, 1973.

MEYER, Marlyse. Folhetim: Uma história. São Paulo: Companhia das Letras, 1996.

QUEIRÓS, Eça de. O Primo Basílio. São Paulo: Klick, 1997.

SOBREIRA, Luis. "Uma imagem do campo literário português no período romântico través dos best sellers produzidos entre 1840 e 1860". Artigo apresentado no IV Congresso Internacional da Associação Portuguesa de Literatura Comparada. Évora: 2001.

VASCONCELOS, Sandra Guardini. Dez lições sobre o romance inglês do século dezoito. São Paulo: Boitempo, 2002.

VILELA, Ana Luisa. "Primatas e carnívoros n'Os Maias: elementos discursivos do erótico queirosiano a propósito de um ananás comido na Toca.” In: MINÉ, Elza (org.) 150 anos com Eça de Queirós. São Paulo: Centro de Estudos Portugueses, 1997, pp. 57-71. 